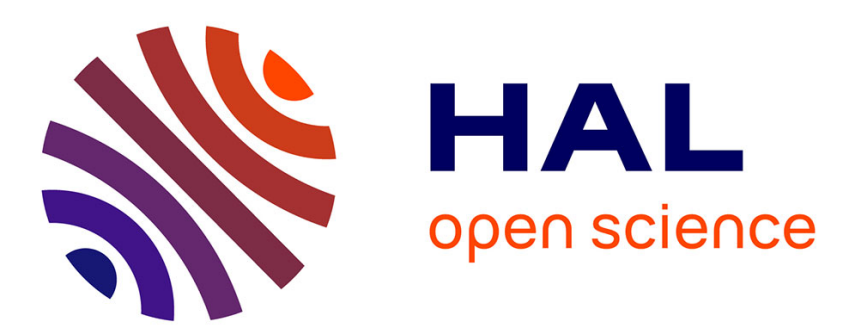

\title{
Results from the Jet Propulsion Laboratory stratospheric ozone lidar during STOIC 1989
}

I. Stuart Mcdermid, Sophie Godin, T. Daniel Walsh

\section{To cite this version:}

I. Stuart Mcdermid, Sophie Godin, T. Daniel Walsh. Results from the Jet Propulsion Laboratory stratospheric ozone lidar during STOIC 1989. Journal of Geophysical Research: Atmospheres, 1995, 100 (D5), pp.9263-9272. 10.1029/94JD02148 . insu-03085948

\section{HAL Id: insu-03085948 \\ https://hal-insu.archives-ouvertes.fr/insu-03085948}

Submitted on 5 Feb 2021

HAL is a multi-disciplinary open access archive for the deposit and dissemination of scientific research documents, whether they are published or not. The documents may come from teaching and research institutions in France or abroad, or from public or private research centers.
L'archive ouverte pluridisciplinaire HAL, est destinée au dépôt et à la diffusion de documents scientifiques de niveau recherche, publiés ou non, émanant des établissements d'enseignement et de recherche français ou étrangers, des laboratoires publics ou privés. 


\title{
Results from the Jet Propulsion Laboratory stratospheric ozone lidar during STOIC 1989
}

\author{
I. Stuart McDermid, Sophie M. Godin, and T. Daniel Walsh \\ Jet Propulsion Laboratory, Table Mountain Facility, California Institute of Technology, Wrightwood
}

\begin{abstract}
Stratospheric ozone concentration profiles measured by the Jet Propulsion Laboratory differential absorption lidar system during the Stratospheric Ozone Intercomparison Campaign in July/August 1989 are presented. These profiles are compared with the mean profiles based on all of the measurements made by the different participating instruments. The results from the blind intercomparison showed that the lidar results agreed with the overall Stratospheric Ozone Intercomparison Campaign average profile to better than $5 \%$ between 21 and $45 \mathrm{~km}$ altitude. At $20 \mathrm{~km}$ the difference was $\sim 10 \%$, as it was also in the region from 47 to $50 \mathrm{~km}$ altitude. Some systematic features were observed in the comparison of the blind results and these were subsequently investigated. The results of this investigation allowed the analysis algorithm to be refined and improved. The changes made are discussed and the comparison of the refined results showed agreement with the STOIC average to better than $4 \%$ from 18 to $48 \mathrm{~km}$ altitude. For both cases the results above $45 \mathrm{~km}$ altitude are subject to the greatest uncertainty and error and are of questionable value even though they agree within $10 \%$ with the STOIC average. Examples of comparisons of individual lidar profiles with each of the other instruments are also presented.
\end{abstract}

\section{Introduction}

The development of a differential absorption lidar (DIAL) for long-term measurements of stratospheric ozone and for potential inclusion in the Network for the Detection of Stratospheric Change (NDSC) began in 1986, concurrent with the first workshop that considered the priorities and appropriate measurement techniques for such a network [Upper Atmosphere Research Program (UARP), 1986]. The DIAL system at the Jet Propulsion Laboratory Table Mountain Facility (JPL TMF) commenced regular measurements of ozone concentration profiles in February 1988. During the first year of operation, ozone profiles were measured on 111 different nights and during 1989, 158 independent measurements were made. (Note added in proof: By December 31, 1992, some 549 ozone profiles had been measured [McDermid, 1993]). To obtain an initial evaluation of the quality of the lidar results, two intercomparisons were carried out in 1988. The first of these [McDermid et al., 1990a] compared both individual profiles and seasonal variations (monthly means) measured by the lidar and by the Stratospheric Aerosol and Gas Experiment (SAGE II). This study showed good overall agreement between the lidar and SAGE II results in terms of the observed seasonal variations and also for one-to-one comparisons when the measurements were almost simultaneous in time and space. A second, informal intercomparison of a number of different instruments was carried out in southern California during October and November 1988 [McDermid et al., 1990b, c; McGee et al., 1990]. This study compared results from two lidars (JPL and Goddard Space Flight Center (GSFC)), electrochemical concentration cell (ECC) balloon sondes, ROCOZ A rocket

Copyright 1995 by the American Geophysical Union.

Paper number 94JD02148.

0148-0227/95/94JD-02148\$05.00 sondes, and SAGE II and showed that good agreement, to better than $10 \%$, could be obtained if the measurements were made close together in both time and space. It also indicated the usefulness of coincident meteorological data in interpreting apparent anomalies in the ozone data. The lessons learned in conducting these preliminary intercomparisons were heeded in designing the first formal NDSC-sponsored intercomparison, Stratospheric Ozone Intercomparison Campaign 1989 (STOIC 1989), that is the subject of this and other papers in this issue of JGR. The details and rationale for this campaign are described in the overview paper [Margitan et al., this issue].

\section{Experiment}

Complete details of the JPL TMF differential absorption lidar system and the data analysis procedures have been published elsewhere [McDermid and Godin, 1989; McDermid et al., 1990d, e] and only a brief overview will be presented here. A high-power $(100 \mathrm{~W})$ xenon chloride $(\mathrm{XeCl})$ excimer laser provides directly the absorbed, probe wavelength at $308 \mathrm{~nm}$. The reference wavelength, $353 \mathrm{~nm}$, is generated by stimulated Raman shifting of a portion of the fundamental beam in a high-pressure (400 psig) hydrogen cell. Thus the two wavelengths are transmitted simultaneously in time and, by careful alignment, in space. The radiation backscattered by the atmosphere is collected with a 90-cm-diameter telescope and the two wavelengths are separated by a series of dichroic beamsplitters and interference filters. The signal is then measured using photomultipliers and photon-counting techniques. To extend the dynamic range of the counting system and, consequently, the range of the profile, the signal is divided in the approximate ratio 100:1 and directed through separate detection chains. (Note that in the initial configuration this splitting ratio was 10:1 but was changed prior to the STOIC campaign). Two 
Table 1. Vertical Resolution and Typical Statistical Error As a Function of Altitude

\begin{tabular}{ccc}
\hline $\begin{array}{c}\text { Altitude, } \\
\text { km }\end{array}$ & $\begin{array}{c}\text { Range } \\
\text { Resolution, } \\
\text { km }\end{array}$ & $\begin{array}{c}\text { Statistical } \\
\text { Error, } \\
\text { Typical, } \\
\%\end{array}$ \\
\hline Below 33.8 & 0.9 & $<1$ \\
$33.8-38.0$ & 1.7 & $<1$ \\
$38.0-41.0$ & 2.5 & $<1-3$ \\
$41.0-43.4$ & 3.3 & $1-4$ \\
$43.4-45.2$ & 4.1 & $2-5$ \\
$45.2-47.0$ & 4.9 & $2-10$ \\
$47.0-48.2$ & 5.7 & $3-15$ \\
$48.2-49.4$ & 6.5 & $5-25$ \\
$49.4-50.6$ & 7.3 & $5-25$ \\
\hline
\end{tabular}

ozone profiles are therefore calculated, based on the highand low-intensity data, which overlap in the region between approximately 25 and $40 \mathrm{~km}$ altitude. The high-intensity data are saturated at low altitudes and the low-intensity data have poor signal-to-noise ratio at high altitudes. A composite profile is then made up of the low-intensity data at low altitudes and the high-intensity data at the higher altitudes. The effects of saturation of the photon-counting system and the optimum altitude for the crossover from the low- to the high-intensity data will be discussed in some detail later in this paper.

The system operates only at night and the signal is averaged for $10^{6}$ laser pulses, which takes approximately 2 hours, to derive a single stratospheric ozone profile. The ozone number density is obtained from the difference of the derivatives of the signals recorded for each wavelength, divided by the ozone differential absorption cross section, taking into account the temperature dependence of this cross section. The slope (derivative) of the background corrected signal is computed as a function of range. As the altitude is increased, the range resolution of the measurement has to be degraded to limit the increase in the statistical error related to the rapid decrease in the signal level. To effect this compromise, the cutoff frequency of the low-pass derivative filter is made to vary with altitude. The resulting altitude resolution and typical statistical errors are given in Table 1. Corrections to the raw data are made for the Rayleigh scattering and extinction terms, but no corrections for aerosols are made. The parameters required for the Rayleigh and temperature corrections are obtained from the COSPAR reference atmosphere monthly tables [Rees et al., 1990], interpolated to the correct latitude for Table Mountain Facility (TMF). At this point in time, because of the low background level of aerosols in the stratosphere, this neglect of aerosol corrections appears to have negligible influence on the derived ozone profile. In this particular lidar implementation the largest source of error has been found to be associated with the determination of the background signal. This important factor will also be discussed in detail below.

\section{Results, Blind Intercomparison}

The period of the official STOIC intercomparison extended for 14 days from July 20 through August 2, 1989. The JPL lidar made measurements during the 3 hours of darkness preceding local (PDT) midnight, 0400-0700 UT, which then allowed the GSFC lidar to operate from midnight until dawn. As we have described previously [McDermid et al., 1990c], it was not possible to operate the lidars simultaneously because the asynchronous observation of laser pulses from the other system caused nonrandom fluctuations in the background levels. The only exception to this timetable was on the final day, August 2, when a problem with one of the laser amplifiers delayed the start time of the JPL experiment to 0930 UT. Ozone measurements were made for every night of the intercomparison period although the atmospheric conditions for lidar measurements were marginal on several of the nights.

For the blind intercomparison the complete lidar ozone profiles, from 20 to $50 \mathrm{~km}$ altitude, were submitted and no data were excluded even when the signal-to-noise ratio of the measurements was decreased because of clouds or poor atmospheric visibility. Since comparison and review of the blind data set allowed some improvements to be made to the data analysis algorithm, this paper will concentrate on these modifications and comparisons with the final, refined results. However, it is appropriate to consider the results of the blind intercomparison which indicated the areas where some improvements were possible.

Figure 1 shows the average, and $1 \sigma$ standard deviation, of the 14 lidar ozone profiles from the blind data set. The large standard deviations near the top of the profile, i.e., above $\sim 40 \mathrm{~km}$, reflect the instrumental uncertainties at these altitudes since the atmospheric variability in this region, over the period of the campaign, should be negligible. At lower altitudes, below $\sim 30 \mathrm{~km}$, the instrumental uncertainties are combined with a small degree of atmospheric variability that was observed by all of the instruments.

In Figures $2 \mathrm{a}-2 \mathrm{~m}$ the lidar ozone profiles have been compared, on a daily basis, to the average of all of the measurements made each day. The average of these daily differences is then shown in the summary plot in Figure 20. In these and subsequent figures showing percentage differences in ozone, negative values denote lower ozone concentrations measured by the lidar. Three significant features were noted from this comparison. First, at $45 \mathrm{~km}$ the

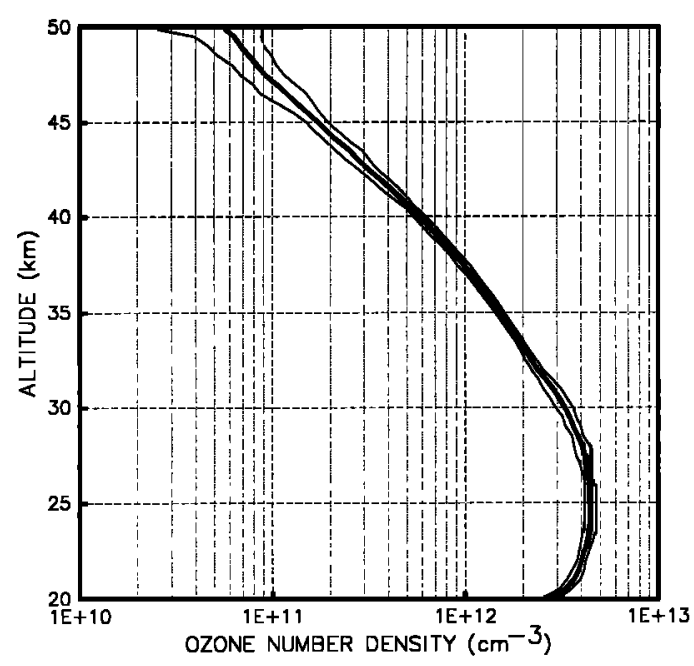

Figure 1. Mean (thick line) and $1 \sigma$ standard deviation (thin lines) of the 14 JPL lidar profiles comprising the blind results set. 
difference curve has an obvious inflection and the magnitude of the difference starts to increase rapidly. Second, there is a small, consistent difference, of the order of $5 \%$, just above $30 \mathrm{~km}$ altitude where the high- and low-intensity profiles were joined together. Third, the very first point, at $20 \mathrm{~km}$ altitude, was always low by approximately $10 \%$. These three points were then carefully studied to see if there was a scientifically justifiable explanation and possible correction.

\section{Refined Data Analysis}

The problem identified at $20 \mathrm{~km}$ was caused by an error in the data analysis algorithm that incorrectly considered the raw data at lower altitudes in calculating the derivative of the signal at $20 \mathrm{~km}$. This was readily corrected by starting the analysis calculations at a lower altitude.

The original rationale for using high- and low-intensity data to form a composite ozone profile was to avoid the need to apply a saturation correction to the raw data counts. It was apparent from the blind intercomparison that the highintensity data still showed a small degree of saturation immediately above the crossover point. There were two potential solutions to this problem. The first was to utilize a) $7 / 20$

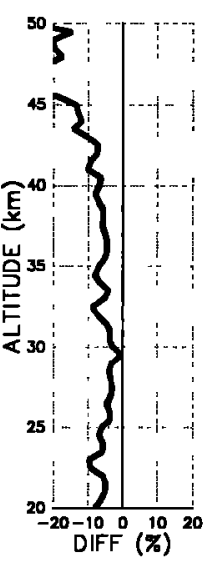

e) $7 / 24$

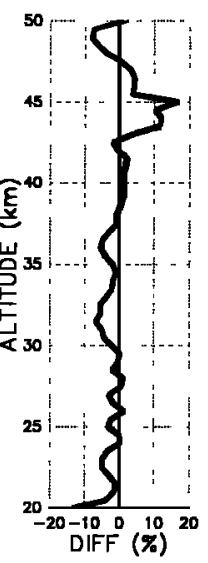

b) $7 / 21$

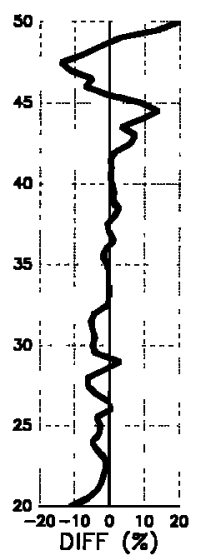

f) $7 / 25$

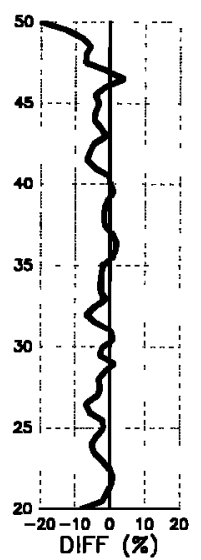

c) $7 / 22$

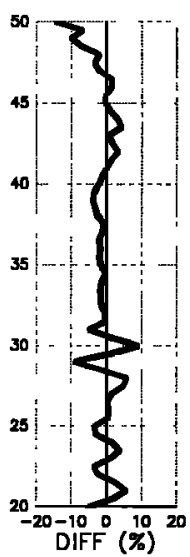

g) $7 / 26$

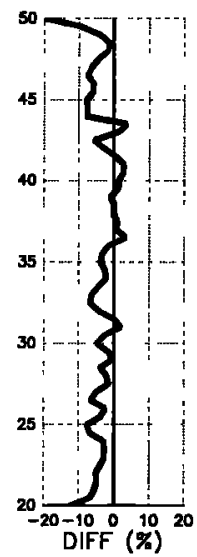

d) $7 / 23$

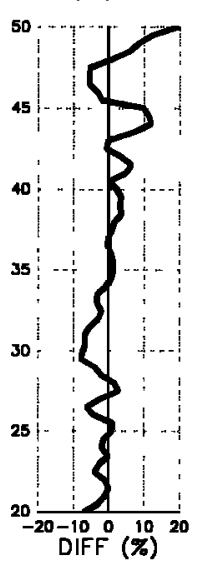

h) $7 / 27$

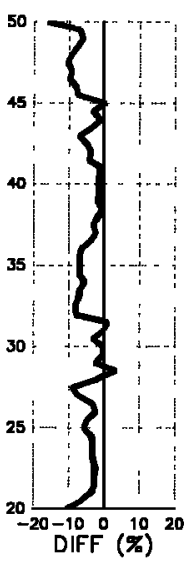

Figure 2. Comparisons of the blind results set: (a)-(m) Percentage difference of the Jet Propulsion Laboratory (JPL) lidar profiles compared to the daily average of all of the blind measurements. (o) Mean difference of the 14-day lidar average compared to the overall Stratospheric Ozone Intercomparison Campaign (STOIC) blind average. i) $7 / 28$

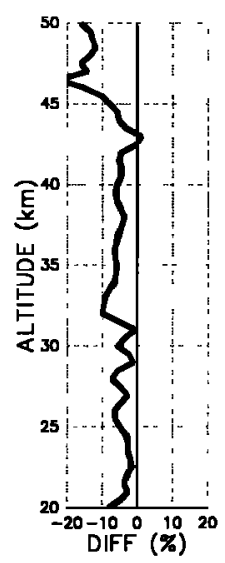

m) 8/01

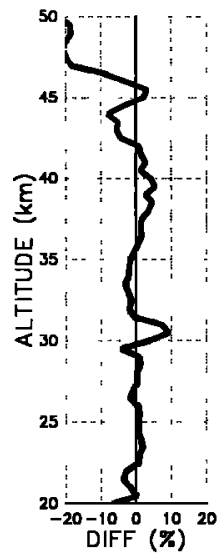

j) $7 / 29$

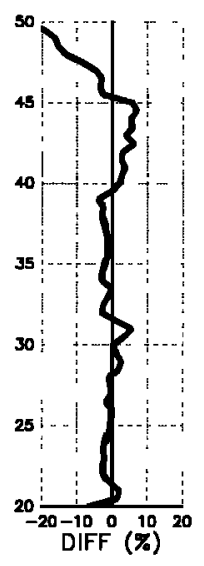

n) $8 / 02$

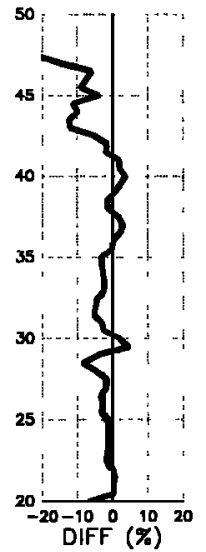

k) $7 / 30$

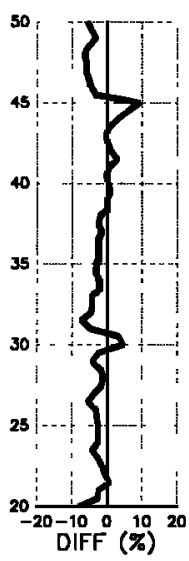

1) $7 / 31$

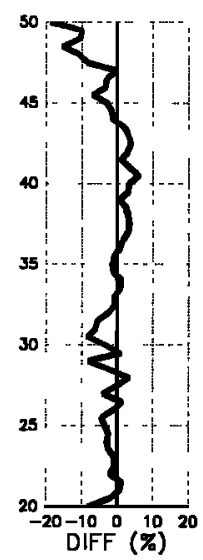

०)BLIND : MEAN

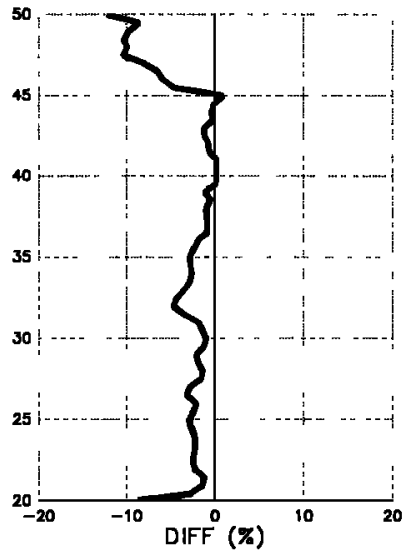

Figure 2. (continued)

the low-intensity data up to a higher altitude were it was certain that the high-intensity data were not saturated. This approach was rejected because the signal-to-noise ratio of the low-intensity data was falling rapidly and the errors in the ozone concentration would be increased significantly in this region. The second approach, which was adopted, was to apply a correction for saturation or pulse pile-up caused by the finite dead-time of the photon-counting system.

For the type of photon-counting system employed by the lidar the system cannot register a second photon pulse until a specific time interval has elapsed. This time interval is known as the dead time $(\tau)$ and the counters will remain paralyzed, i.e., will not register further photons, until a free interval of at least the dead time has elapsed. This phenomenon is well known, has been extensively studied, and appropriate correction algorithms are available for a wide variety of situations (see, for example, the following treatises and references therein: Cantor and Teich [1975], Evans [1955], and Saleh [1978]).

Based on the Poisson characteristics of the photoncounting process and the fact that this system can be paralyzed, then, as the true count rate increases, the observed count rate, $N_{c}$, passes through a maximum given by

$$
N_{c}=\frac{1}{e \tau}
$$




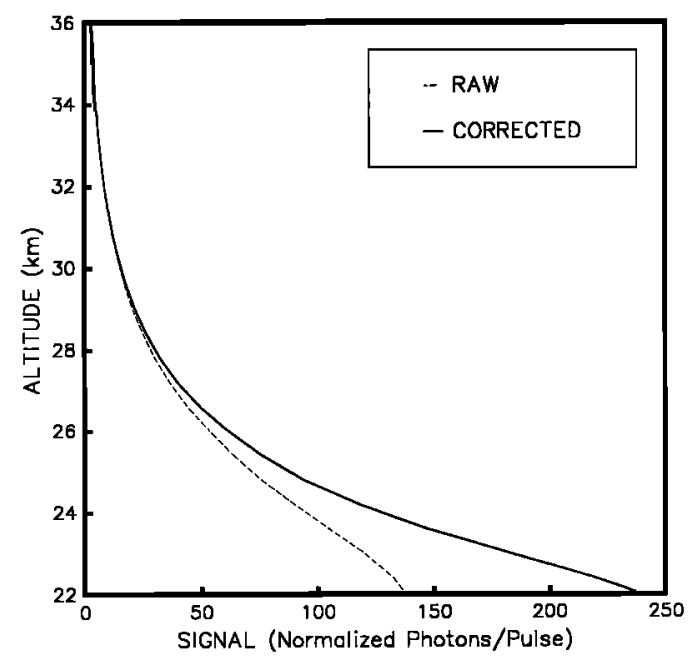

Figure 3. Effects of the photon-counting saturation correction on the raw data from the 308-nm high-intensity channel, for the July 20 experiment.

This relationship can be used to confirm the experimental value for the dead time. The highest counts observed experimentally were in the range $145-160$ in a 4- $\mu$ s time bin, which are equivalent to count rates of $36-40 \mathrm{MHz}$. Using these values in (1) gives a range for the dead time of 9.2-10.1 ns or a system specification of $100-108 \mathrm{MHz}$. The slowest components in the acquisition system are the multichannel scaler (MCS) and the pulse-height-discriminator which are specified by the manufacturer at 100 and $110 \mathrm{MHz}$, respectively. The observed maximum count rates are therefore in perfect accord with these specifications which provides confidence in assigning a dead time to use in the saturation correction procedure.

The definition of the dead time forbids counts greater than $T / \tau$ where $T$ is the counting time interval, i.e., dwell time of the MCS, and thus the system will still reach saturation when the specified maximum rate of the system is reached. Below this level, the number of photons counted, $N_{c}$, as a function of the number actually received, $N_{r}$, is given by the formula

$$
N_{c}=1+\left[\left(1-\frac{\tau}{T}\right) N_{r-1}\right] \exp -\left(\frac{N_{r} \tau}{T}\right)
$$

As indicated above, the dead time was determined to be in the range 9.2-10.1 ns for the high-intensity 308-nm channel. Since the other channels are not driven to saturation to the same degree as this channel, it is not possible, under normal experimental conditions, to determine the dead time of each channel individually from the raw data. Therefore it was assumed that the dead time was constant for all channels, and in order not to overcorrect the data the shorter dead time of $9.2 \mathrm{~ns}$ was used in the calculations. This is justifiable since each channel is identical in terms of the types of photomultipliers and signal detection electronics. Also, by testing the sensitivity of the derived ozone profiles to different values for the dead time, it was found that no discernible differences in the composite profile could be found for $10 \%$ variations of the dead time.

Equation (2) is inverted in order to obtain the true counts as a function of the observed counts. Figure 3 shows the effects of this correction procedure on the 308-nm highintensity data recorded on July 20 , the first day of STOIC. The saturation correction does not become negligible until an altitude of $\sim 35 \mathrm{~km}$. The correction procedure was applied to all channels, including the low-intensity data. Figure 4 shows the dramatic effect of the saturation correction on the derived ozone profiles. The profile derived from the highintensity data is shown by the solid line and that from the low-intensity data by the dashed line. The low intensity profile is unchanged by the saturation correction procedure, indicating that the signal intensity in these channels was low enough not to cause any pulse pile-up and that the correction algorithm does not induce changes when the data are not saturated. The ozone profile from the high-intensity data is unchanged only above $\sim 35 \mathrm{~km}$. Below this altitude the profile is changed significantly. As can be seen in Figure 4, the agreement between the high- and the low-intensity profiles is excellent and is extended downward to $\sim 25 \mathrm{~km}$ which further gives confidence in the correctness of the saturation correction procedure. The profile derived from the high-intensity data has better signal to noise and hence smaller statistical errors and it is therefore advantageous to be able to move the crossover point for the composite profile to a lower altitude. The photon-counting system still reaches a true saturation at $\sim 100 \mathrm{MHz}$ which is indicated by the profile falling to zero immediately below the maximum. The low-intensity data were not saturated at all, but the effect of
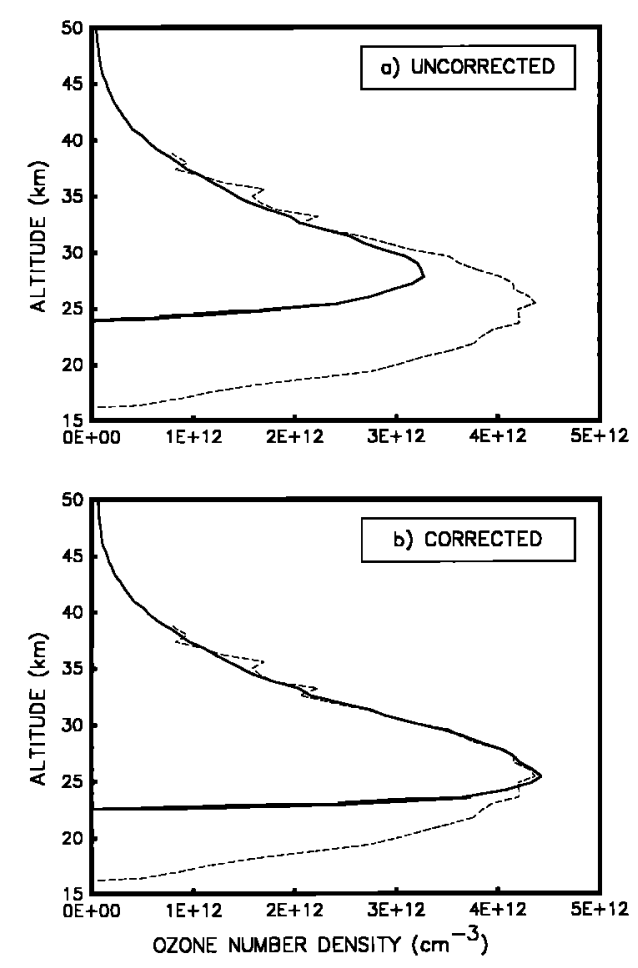

Figure 4. (a) Ozone profiles derived from the highintensity (solid line) and low-intensity (dashed line) data without saturation correction. These are blind results from July 20 and the low to high crossover selected was at $32 \mathrm{~km}$. (b) The same profiles but with the saturation correction applied. These now constitute refined results. The low to high crossover was at $28 \mathrm{~km}$ and the agreement between the high and the low profiles is significantly improved. 
the electronic gates on the photomultipliers is shown by the profile falling to zero at $\sim 16 \mathrm{~km}$. With the new analysis procedure the ozone profile was extended down to $17 \mathrm{~km}$, limited by the electronic gates. These gates have since been shifted to allow the lower limit of the profile to be extended down to $15 \mathrm{~km}$.

At the upper end of the altitude range, the high-intensity data, and in particular the 308-nm channel, have been seen to be affected by a signal-induced noise [McDermid et al., $1990 \mathrm{~d}$ ]. It has been determined that this is caused by the very high intensity of laser radiation backscattered from the boundary layer and the lower troposphere hitting the photocathodes of the photomultiplier detectors. This signal is not transmitted by the photomultiplier since it is electronically gated off during this time, but the dark current of the tube shows a delayed recovery [Lee et al., 1990]. The effect of this signal-induced noise is to increase and cause a curvature of the background level. Different methods of fitting the background have been studied [McDermid et al., 1990d; likura et al., 1987] and the best fit is given by a nonlinear least squares exponential regression. The ozone profile below $\sim 40-45 \mathrm{~km}$ is insensitive to the method used to estimate the background. However, above this altitude the profile is very sensitive to the background correction. For the nonlinear exponential fit it is also found that the profile is sensitive to the starting altitude of the regression. An important factor in the background estimation is that the real signal must be negligible at the starting altitude, but the fit must be started as low as possible in order to evaluate the curvature correctly. Various methods have been used to select the starting altitude and these were reconsidered in refining the data analysis. However, no suitable, justifiable modification could be identified. For the final refined results, the background fitting for the 308-nm high-intensity channel was started at $85 \mathrm{~km}$ for all data sets.

The only improvement in the agreement of the results above $45 \mathrm{~km}$ was achieved by eliminating some of the results. Based on consideration of the signal levels which were affected by clouds or other conditions, some of the profiles were terminated at $47 \mathrm{~km}$ instead of $50 \mathrm{~km}$. Table 2

Table 2. Atmospheric and Experimental Conditions Relating to the Maximum Altitudes for the Profiles in the Refined Results Set

\begin{tabular}{|c|c|c|}
\hline Date & $\begin{array}{c}\text { Maximum } \\
\text { Altitude, } \\
\text { km }\end{array}$ & Comment \\
\hline July 20, 1989 & 47 & $\begin{array}{l}\text { some high clouds, poor sky } \\
\text { clarity }\end{array}$ \\
\hline July 21, 1989 & 47 & clouds toward end of experiment \\
\hline July 22, 1989 & 50 & $\begin{array}{l}\text { experiment terminated early due } \\
\text { to clouds }\end{array}$ \\
\hline July 23, 1989 & 42 & alignment problem \\
\hline July 24,1989 & 50 & \\
\hline July 25,1989 & 50 & \\
\hline July 26,1989 & 50 & some high clouds \\
\hline July 27,1989 & 50 & \\
\hline July 28,1989 & 50 & \\
\hline July 29,1989 & 50 & \\
\hline July 30,1989 & 50 & \\
\hline July 31, 1989 & 47 & poor sky clarity (smoke haze) \\
\hline August 1,1989 & 50 & \\
\hline August 2, 1989 & 47 & laser amplifier breakdown \\
\hline
\end{tabular}

a) $7 / 20$

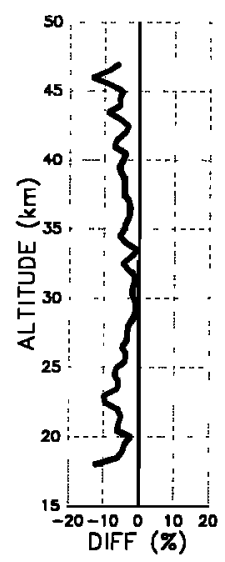

b) $7 / 21$

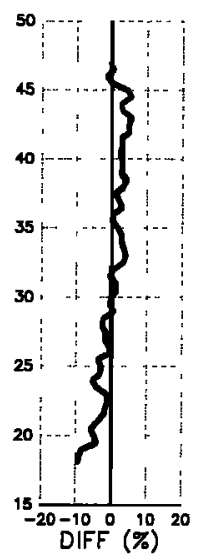

c) $7 / 22$

d) $7 / 23$
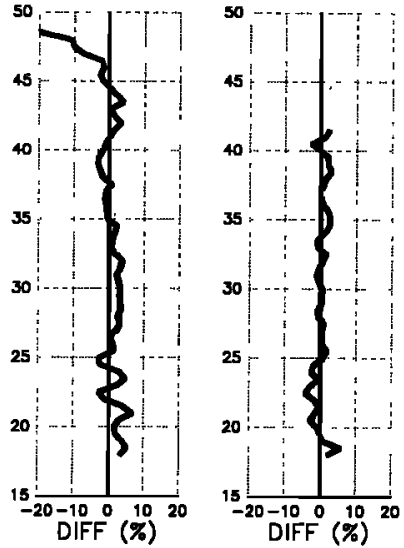

e) $7 / 24$

f) $7 / 25$

g) $7 / 26$

h) $7 / 27$
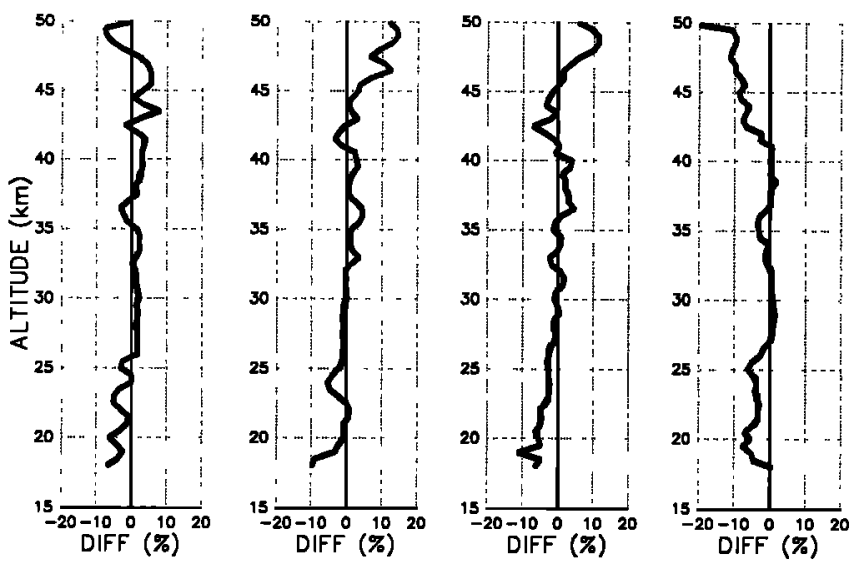

Figure 5. Same as Figure 2 but for comparisons of the refined results set. (a)-(m) Percentage difference of the JPL lidar profiles compared to the daily average of all of the refined measurements. (o) Mean difference of the 14-day lidar average compared to the overall STOIC refined average.

shows the dates, maximum altitudes reached, and comments on conditions affecting the experiment.

To minimize the error in the ozone concentration in the upper range and to perform systematic reliable measurements at $50 \mathrm{~km}$, mechanical gating of the photomultipliers would be required.

\section{Results, Refined Intercomparison}

As for the blind data set, Figures $5 \mathrm{a}-5 \mathrm{~m}$ shows the difference of the JPL lidar profile compared with the average of all profiles measured on a daily basis. The average of these daily differences is shown in Figure 5o. For this comparison the mean difference of the lidar profiles from the average of the other instruments is $4 \%$ or better from 18 to $48 \mathrm{~km}$ altitude. In the region above $45 \mathrm{~km}$ the difference from the STOIC averages and the uncertainties in the lidar results start to increase rapidly. Because of the problems in evaluating and correcting for the background, which affects the profiles only in this region, the results obtained above $45 \mathrm{~km}$ are of questionable value for trend detection even though they agree within $10 \%$ with the STOIC results.

The comparison of averages indicates the general agree- 
i) $7 / 28$

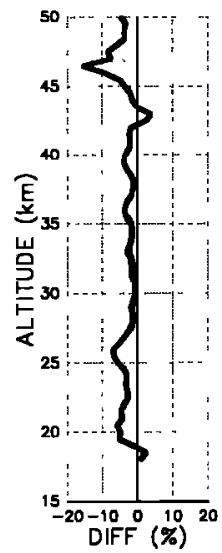

m) $8 / 01$

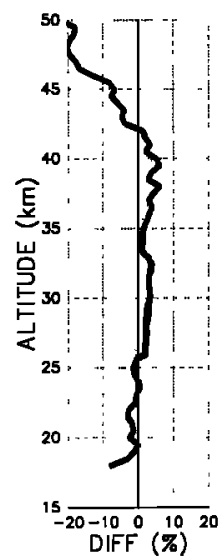

j) $7 / 29$

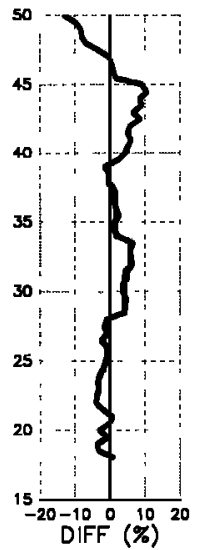

n) $8 / 02$

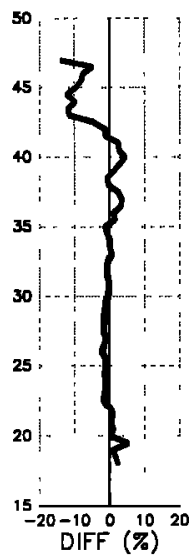

k) $7 / 30$

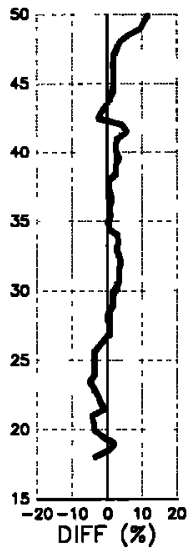

o) REFINED : MEAN

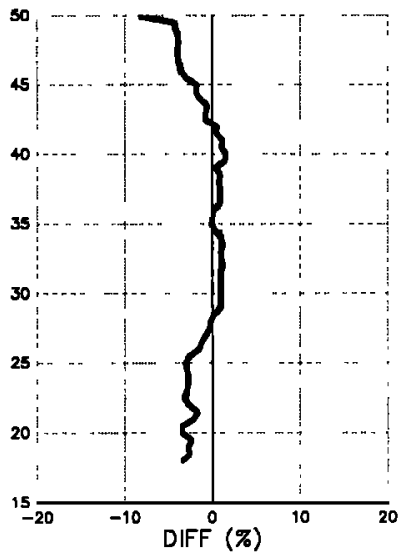

Figure 5. (continued)

1) $7 / 31$

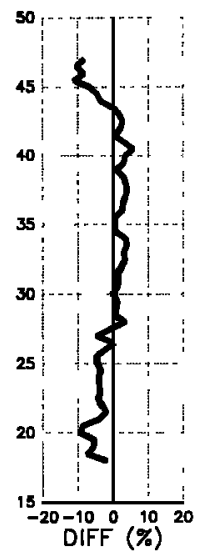
measurements can be said to agree within the error bars $(1 \sigma)$. This is not always the case, which therefore indicates the presence of other error sources.

Figure 6a shows the refined profiles from the JPL and GSFC lidars for July 24, 1989. The JPL profile was recorded between 0440 and $0640 \mathrm{UT}$ and the GSFC profile between 0751 and 1100 UT [McGee et al., this issue], both at TMF. The percentage difference between these two profiles is shown in Figure $6 \mathrm{~b}$. This comparison shows poorer agreement between the lidars than was generally observed during STOIC and previously [McDermid et al., 1990c]. Since they utilize the same technique and similar equipment, the two lidars suffer the same problems, particularly with respect to signal-induced noise at high altitudes [McDermid et al., 1990e; McGee et al., 1991]. Since the GSFC system has slightly lower power than the JPL system, the background
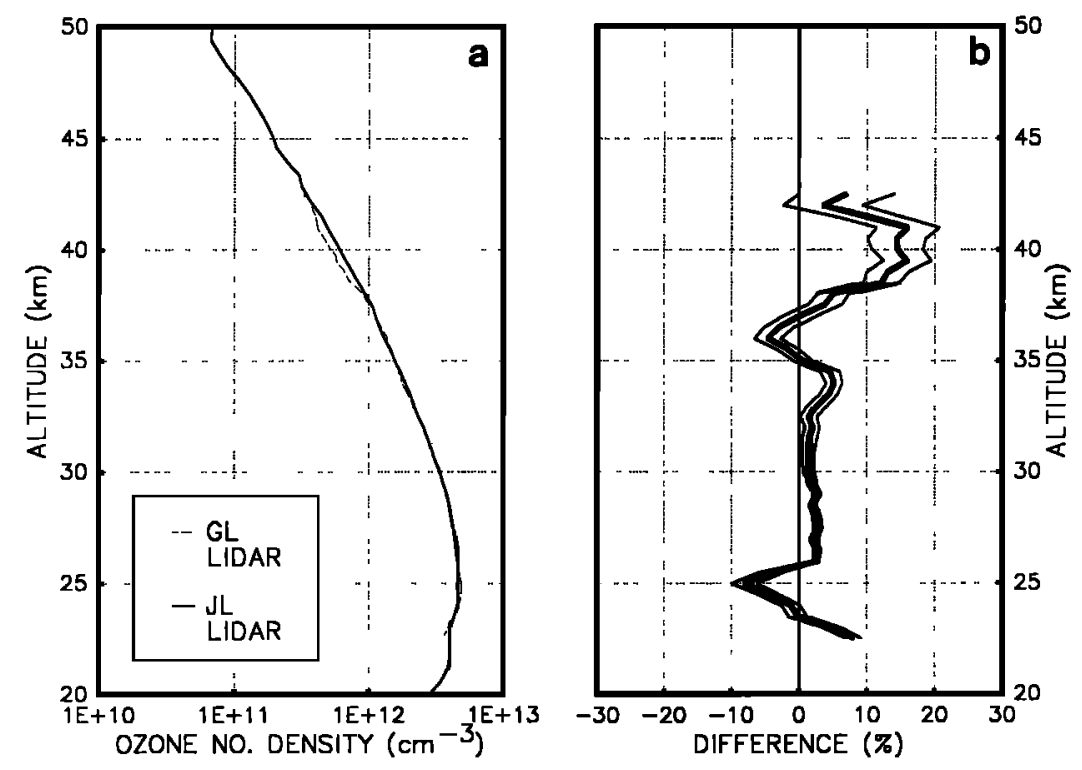

Figure 6. Comparison of the refined profiles recorded by the JPL and the Goddard Space Flight Center lidars on July 24. (a) Ozone concentration profiles. (b) Percentage difference between these profiles with the combination of the statistical errors indicated by the thin lines. 

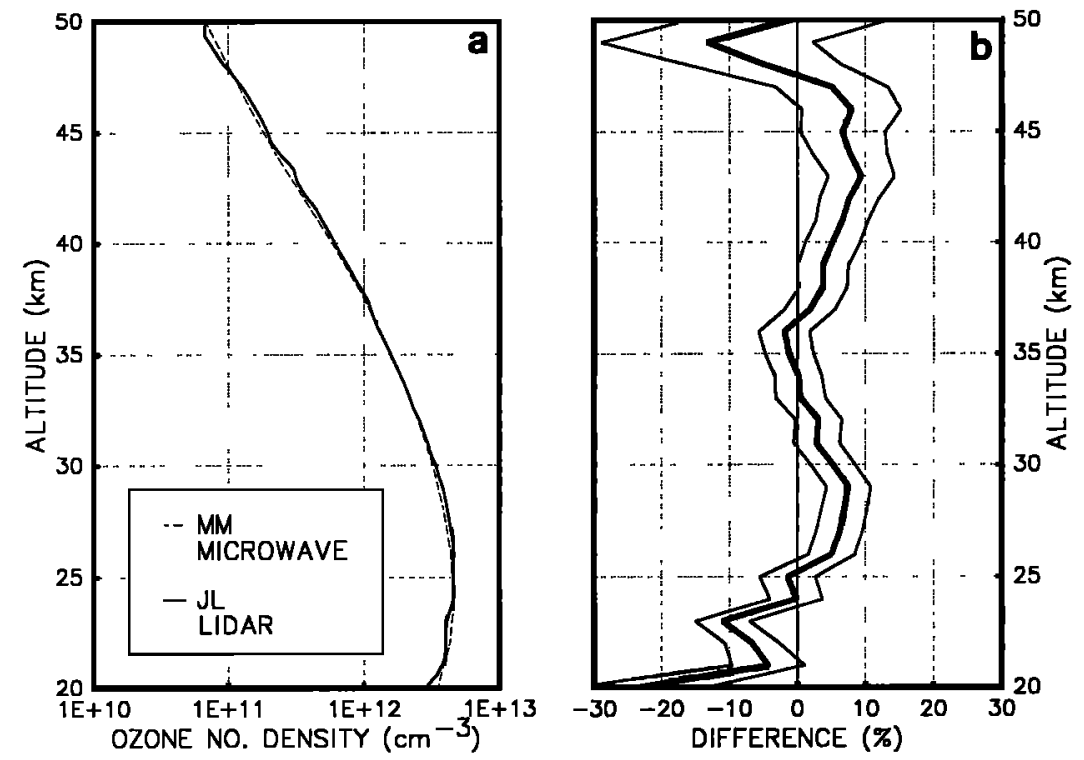

Figure 7. Comparison of the JPL lidar profile with that recorded by the Millitech/LaRC microwave radiometer for July 24 . As Figure 6.

effects are typically seen at a lower altitude and this is reflected in the plots in Figure 6. Through the middle of the range the agreement is very good, i.e., less than $5 \%$ difference from $\sim 25$ to $37 \mathrm{~km}$ altitude and less than $10 \%$ from the start altitude of the GSFC profile at $20 \mathrm{~km}$ to $\sim 38 \mathrm{~km}$ altitude. In general, the range of good agreement, $<10 \%$, extends from $20 \mathrm{~km}$ to above $40 \mathrm{~km}$ altitude.

A comparison of the lidar profile with that measured by the Millitech/Langley Research Center (LaRC) microwave radiometer [Connor et al., this issue], averaged over the period 0400 to 1215 UT, is shown in Figure 7. Agreement to better than $10 \%$ over practically the entire range of the measurement is illustrated in Figure $7 \mathrm{~b}$. The somewhat sigmoid shape of the difference curve was characteristic of all of the lidarmicrowave comparisons during STOIC and the lidar measurement was always lower than the microwave near $20 \mathrm{~km}$ altitude. The Millitech/LaRC microwave instrument continued to operate at TMF through November 1989, following STOIC. A more detailed comparison with the lidar over this extended time period is given by Parrish et al. [1992].

The ROCOZ A rocket ozonesondes were launched from San Nicolas Island, $33.3^{\circ} \mathrm{N}-119.5^{\circ} \mathrm{W}$, and on July 24 the launch time was $1911 \mathrm{UT}$ [Barnes et al., this issue]. As is shown in Figure 8, above the ozone maximum the lidar to ROCOZ A difference is almost constant with the ROCOZ A giving an ozone concentration $\sim 5 \%$ higher than the lidar. This may be a characteristic of the ROCOZ A instrument [Barnes et al., 1989] although the agreement seen during the October-November 1988 intercomparison was better [McDermid et al., 1990b].

SAGE II made a sunrise measurement at 1317 UT, July 24 , and at a tangent point $31.2^{\circ} \mathrm{N}-120.7^{\circ} \mathrm{W}$ which is $536 \mathrm{~km}$
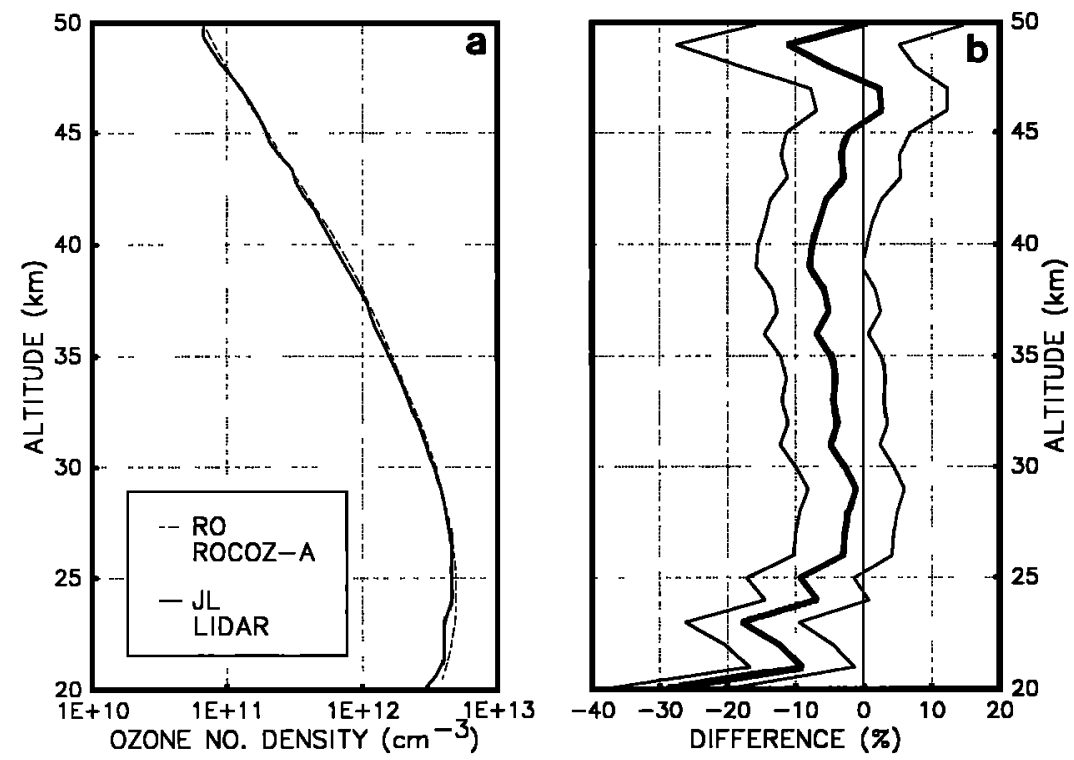

Figure 8. Comparison of the ROCOZ A and JPL lidar profiles for July 24. As Figure 6. 

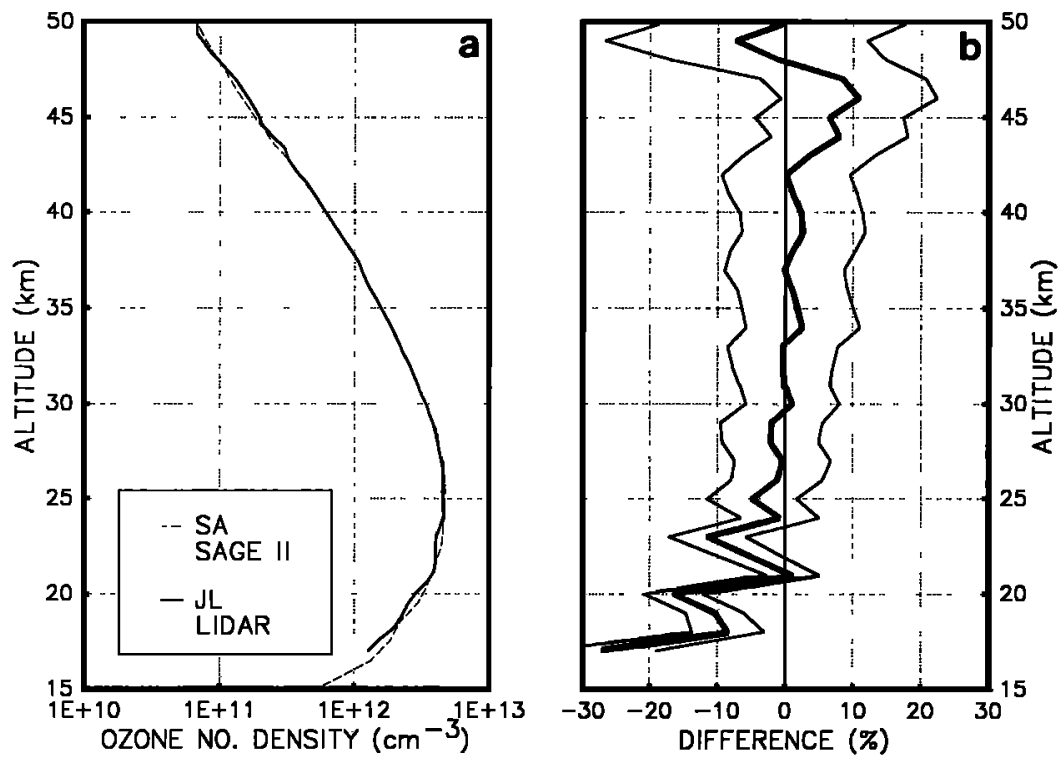

Figure 9. Comparison of the SAGE II satellite measurement with the JPL lidar profile for July 24 . As Figure 6.

from TMF. The agreement between the lidar and the SAGE II profiles, Figure $9 a$ and $9 b$, is excellent showing $<5 \%$ difference from the ozone maximum to above $40 \mathrm{~km}$ (i.e., $\sim 24-44 \mathrm{~km}$ ) where the lidar data signal-to-noise ratio starts to fall. This is typical of the agreement seen between the JPL lidar and the SAGE II over an extended period for SAGE II measurements made within $1000 \mathrm{~km}$ of TMF [McDermid et al., 1990a]. However, below the ozone maximum the two profiles start to diverge with the lidar data typically showing lower ozone concentrations than SAGE II, similar to the comparison with the microwave radiometer.

In Figures 10 and 11 the lidar results are compared with those obtained from the balloon ECC sondes launched by the National Oceanic and Atmospheric Administration
(NOAA) [Komhyr et al., this issue] and by Wallops Flight Facility (WFF) [Barnes and Torres, this issue]. On July 24 the WFF sonde was launched at $0546 \mathrm{UT}$ and the NOAA sonde at 0559 UT, both from TMF. In Figures 10a and 11a the ozone number density axis has been changed to a linear scale which shows more clearly the structure in the ozone profile at the lower altitudes. Because of the relatively slow ascent rate of the balloons the vertical resolution of the ECC measurements is the best of all of the instruments in STOIC. Small features were observed in the ozone profile by the sondes and these are reproduced, with only minimal smoothing, by the lidar. The agreement in the values obtained for the ozone concentration as well as in the shape of the profile is also good except for the first point of the lidar profile.
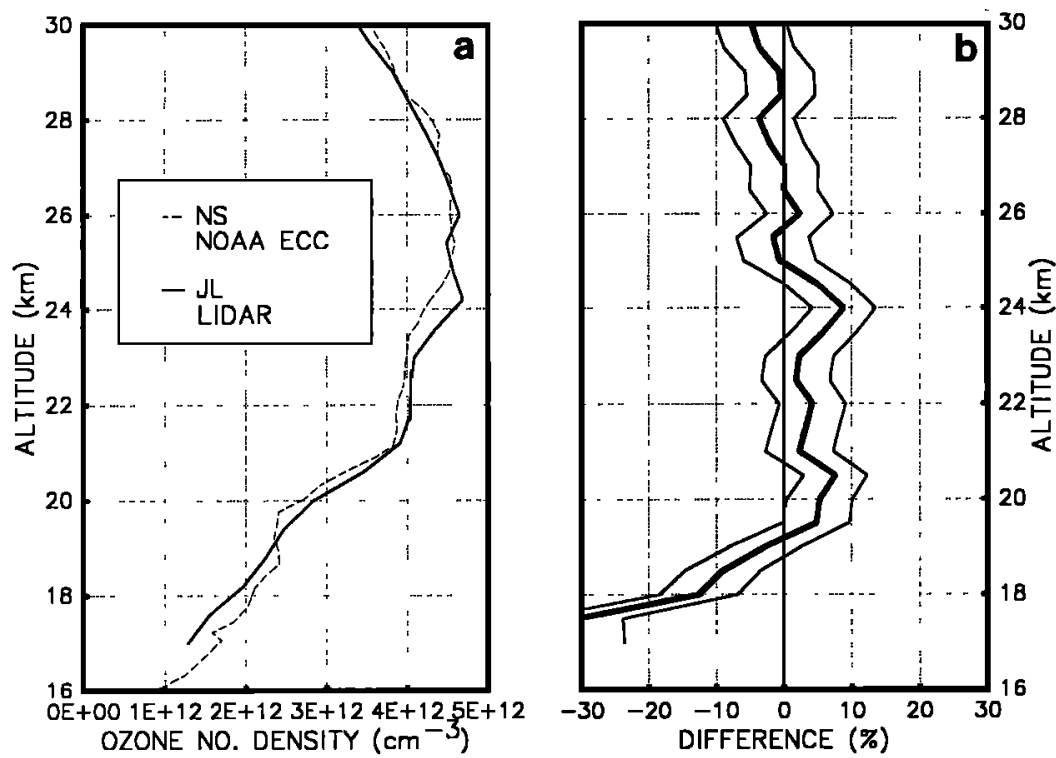

Figure 10. Comparison of the JPL lidar profile with that recorded by the NOAA electrochemical concentration cell balloon sonde on July 24. As Figure 6. Note the features in the ozone profile in this altitude range that are observed by both instruments (compare Figure 11). 

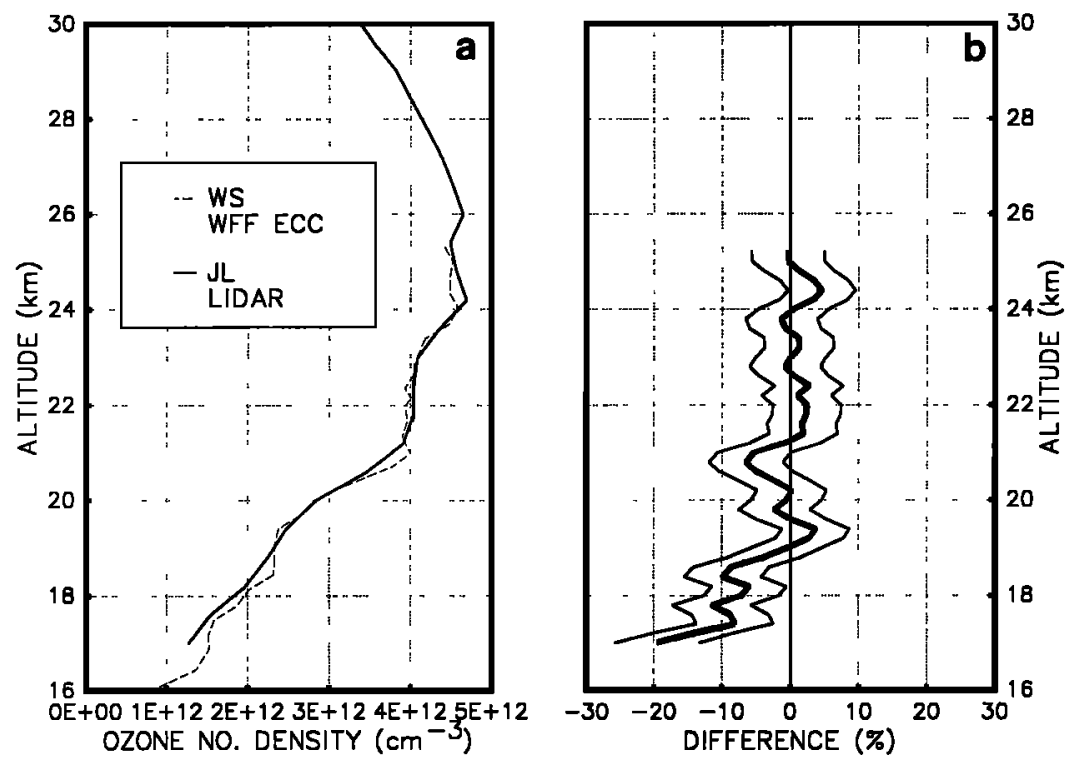

Figure 11. Comparison of the JPL lidar profile with that recorded by the Wallops Flight Facility ECC balloon sonde on July 24 . As Figure 6 . Note the features in the ozone profile in this altitude range that are observed by both instruments (compare Figure 10).

\section{Summary}

STOIC has represented a very important stage in the development of the differential absorption lidar for its proposed role in the NDSC and for correlative measurements with the Upper Atmosphere Research Satellite (UARS) and other satellite programs. It has provided a unique opportunity to test some of the alternative procedures in the data analysis and has allowed the ozone concentration profile algorithm to be improved. The need for hardware modifications to reduce the effects of signal-induced noise on the high-altitude measurements was also indicated.

It is believed that this study confirms the power of the DIAL technique for making accurate measurements of stratospheric ozone concentration profiles on a regular and long-term basis. The JPL lidar, in its present implementation, has shown agreement with the STOIC average to better than $4 \%$ from 18 to $48 \mathrm{~km}$ altitude. The results above $45 \mathrm{~km}$ altitude are subject to the greatest uncertainty and error and are of questionable value even though they agree within $10 \%$ with the STOIC average. The lidar compared well with other techniques and appears capable of providing reliable and reproducible results. Studies such as STOIC and intercomparisons with other instruments should continue as an ongoing check on the various sensors and to provide validation in the determination of long-term changes.

Acknowledgments. The work described in this paper was carried out at the Jet Propulsion Laboratory, California Institute of Technology, under a contract with the National Aeronautics and Space Administration. We are grateful to the many other participants in the STOIC campaign for their cooperation and for sharing their results.

\section{References}

Barnes, R. A., and A. L. Torres, Electrochemical concentration cell ozone soundings at two sites during the STOIC campaign, $J$. Geophys. Res., this issue.

Barnes, R. A., M. A. Chamberlain, C. L. Parsons, and A. C. Holland, An improved rocket ozone sondes (ROCOZ A), 3,
Northern midlatitude ozone measurements from 1983 to $1985, J$. Geophys. Res., 94, 2239-2254, 1989.

Barnes, R. A., C. L. Parsons, and A. P. Grothouse, ROCOZ A ozone measurements during the Stratospheric Ozone Intercomparison Campaign (STOIC), J. Geophys. Res., this issue.

Cantor, B. I., and M. C. Teich, Dead-time-corrected photo-counting distributions for laser radiation, J. Opt. Soc. Am., 65, 786-791, 1975.

Connor, B. J., A. Parrish, J.-J. Tsou, and M. P. McCormick, Error analysis for the ground-based microwave ozone measurements during STOIC, J. Geophys. Res., this issue.

Evans, R. D., The Atomic Nucleus, chap. 28, Applications of Poisson Statistics to Some Instruments Used in Nuclear Physics, McGraw-Hill, New York, 1955.

likura, Y., N. Sugimoto, Y. Sasano, and H. Shimizu, Improvement on lidar data processing for stratospheric aerosol measurements, Appl. Opt., 26, 5299-5306, 1987.

Komhyr, W. D., R. A. Barnes, J. A. Lathrop, G. B. Brothers, and D. P. Opperman, Electrochemical concentration cell ozonesonde performance evaluation during STOIC 1989, J. Geophys. Res., this issue.

Lee, H. S., G. K. Schwemmer, C. L. Korb, M. Dombrowski, and C. Prasad, Gated photomultiplier response characterization for DIAL measurements, Appl. Opt., 29, 3303-3315, 1990.

Margitan, J. J., et al., Stratospheric Ozone Intercomparison Campaign (STOIC) 1989: Overview, J. Geophys. Res., this issue.

McDermid, I. S., A 4-year climatology of stratospheric ozone from lidar measurements at Table Mountain, $34.4^{\circ} \mathrm{N}$, J. Geophys. Res., 98, 10,509-10,515, 1993.

McDermid, I. S., and S. M. Godin, Stratospheric ozone measurements using a ground-based, high-power lidar, laser applications in meteorology and Earth and atmospheric remote sensing, Proc. SPIE Int. Soc. Opt. Eng., 1062, 225-232, 1989.

McDermid, I. S., S. M. Godin, P. H. Wang, and M. P. McCormick, Comparison of stratospheric ozone profiles and their seasonal variations as measured by lidar and Stratospheric Aerosol and Gas Experiment during 1988, J. Geophys. Res., 95, 5605-5612, 1990a.

McDermid, I. S., et al., Comparison of ozone profiles from groundbased lidar, electrochemical concentration cell balloon sonde, ROCOZ A rocket ozone sondes, and Stratospheric Aerosol and Gas Experiment satellite measurements, J. Geophys. Res., 95, 10,037-10,042, 1990b.

McDermid, I. S., S. M. Godin, L. O. Lindquist, T. D. Walsh, J. Burris, J. Butler, R. Ferrare, D. Whiteman, and T. J. McGee, 
Measurement inter-comparison of the JPL and GSFC stratospheric ozone lidar systems, Appl. Opt., 29, 4671-4676, 1990c.

McDermid, I. S., S. M. Godin, and L. O. Lindquist, Ground-based laser DIAL system for long-term measurements of stratospheric ozone, Appl. Opt., 29, 3603-3612, 1990d.

McDermid, I. S., S. M. Godin, and T. D. Walsh, Lidar measurements of stratospheric ozone and intercomparisons and validation, Appl. Opt., 29, 4914-4923, 1990e.

McGee, T. J., P. Newman, R. Ferrare, D. Whiteman, J. Butler, J. Burris, S. M. Godin, and I. S. McDermid, Lidar observations of ozone changes induced by subpolar air mass motion over Table Mountain (34.4 $\left.{ }^{\circ} \mathrm{N}\right)$, J. Geophys. Res., 95, 20,527-20,530, 1990.

McGee, T. J., D. Whiteman, R. Ferrare, J. Butler, and J. Burris, STROZ LITE: NASA/GSFC Stratospheric Ozone Lidar Trailer Experiment, Opt. Eng., 30, 31-39, 1991.

McGee, T. J., R. A. Ferrare, D. N. Whiteman, J. J. Butler, J. F.
Burris, and M. A. Owens, Lidar measurements of stratospheric ozone during the STOIC campaign, J. Geophys. Res., this issue. Rees, D., J. J. Barnett, and K. Labitzke (eds.), COSPAR International Reference Atmosphere: 1986, II, Middle Atmosphere Models, Adv. Space Res., 10, 1-517, 1990.

Saleh, B., Photoelectron Statistics, Springer Ser. Opt. Sci., vol. 6 , edited by D. L. MacAdam, Springer-Verlag, New York, 1978.

Upper Atmosphere Research Program (NASA-UARP), Network for the Detection of Stratospheric Change, report of the Workshop, Boulder, Colorado, March 5-7, 1986.

S. M. Godin, I. S. McDermid, and T. D. Walsh, Jet Propulsion Laboratory, Table Mountain Facility, P. O. Box 367, California Institute of Technology, Wrightwood, CA 92397-0367.

(Received April 16, 1993; revised August 15, 1994; accepted August 15, 1994.) 